\title{
New Formulation of Dynamic Collaborative Learning to Effectuate of Indonesia Integrated and Open Online Learning (PDITT) Programme
}

\author{
Nurul Hidayat \\ Department of Computer Science, \\ UGM \\ Indonesia
}

\author{
Azhari S.N. \\ Department of Computer Science, \\ UGM \\ Indonesia
}

\begin{abstract}
Portrait of Indonesia has characteristics that are very heterogeneous and dynamic course greatly affect the progress and quality of the education system and learning. Investment and development of infrastructure is one part only of a few things to be prepared properly and comprehensively. Different needs, levels of welfare that has not been evenly distributed, the number of universities that have not been balanced, plus social issues in each region in Indonesia is a complicated issue that should be of particular concern by the government. The method used in this paper is to use two perspectives namely pembelaaran dynamic mapping system, and system architecture mapping of learning. This study contributes to several things: the current situation of the system and the data area of higher education in Indonesia, learning architectures, PDITT framework, dynamic mapping system of collaborative learning, and also benefit from the implementation.
\end{abstract}

\section{General Terms}

Collaborative Learning, Learning Architecture, Indonesia Integrated and Open Online Learning

\section{Keywords}

Dynamic Collaborative Learning, Online Learning, PDITT

\section{INTRODUCTION}

An advance in information technology and communication brings changes in human life. Role of Information and Communication Technology (ICT) increasingly felt in various sectors, particularly in education. The role of ICT in education is expected to improve the quality of education as one of the pillars of education. Improving the quality of education to be a priority with the awareness that the success of a nation in the future is depending on the quality of education. Therefore, the Ministry of Education and Culture of the Republic of Indoneisa is very thoughtfully put the pillars of education through its mission known as $5 \mathrm{~K}$, namely Ketersediaan (availability), Keterjangkauan (affordability), Kualitas and Relevansi (quality and relevance), Kesetaraan and Kepastian (equity and certainty). The origin of learning is one of the aspects in education that should be available, affordable, high quality, relevant to the needs of society, and accessible to all, with no discrimination based on sex, age, religion, race, and is guaranteed certainty in aksesibilitinya. Currently, the achievement of these goals can be done only with one word: technology. The development of information and communication technologies is so rapid; those have an impact on the ease of social networking, and gain access to information, as well as interacting directly without limits of space and time.

The Ministry of Education and Culture of Indonesia (Kemdikbud) always seeks to make improvements systematic, sustained, and comprehensive review of the system of national education through institutional strengthening, improvement of management and the strengthening of human resources and utilization profusely Information and Communication Technology (ICT) to support the achievement of the vision Kemdikbud in Insan Indonesia in 2025 is to realize Intelligent Comprehensive, Competitive, and Dignity. In particular, in the Strategic Plan (Strategic Plan 2010-2014), Kemdikbud also have established Vision 2014 that "The implementation of Prime Services Education to Establish a Comprehensive Intelligent Indonesia Human Resources".

Based on the data of the working population in 2009, which is nearly 100 million, more than 60 percent of educational background in elementary school (SD) or did not complete primary school. In fact, nearly ten years later in 2010 the Indonesian labor is still dominated by graduates from high school (SMA) and Vocational School (SMK) as much as $50 \%$. This condition is not without reason, because one of the major problems faced by this nation is because only a small fraction of them are able to continue their education to the college level. In addition to funding constraints, the limited capacity of the college is also a strategic issue for secondary education graduates to achieve the dream as a scholar. The total number of students from public and private universities, as well as including the Open University students (UT) in 2010 alone was approximately 5.2 million. While the number of Indonesian population aged 19 to 25 years (the age of the potential for learning in college) to 21,184 million, meaning there are about 16 million people in Indonesia have not been able to get an education in college [1].

In 2010, the number of registered universities within the Directorate General of Higher Education is composed of as many as 83 State Universities (PTN) and the 2,933 Private Higher Education (PTS). The existence of such colleges spread across the major cities, provinces, and parts of Indonesia. However, the distribution of colleges in each city, region, or the region where there is uneven or the city very much and college populations elsewhere are very limited and may not even exist.

In line with the distribution of colleges based Kopertis/PTN, and regional as described above, where the college has spread throughout the province. That is, in every province in Indonesia has established a college of varying amounts. 
Table 1. The number of colleges in the Higher Education environment based on the province where the organization of educational activities

\begin{tabular}{|c|c|}
\hline Num. Province Name & Total \\
\hline 1 DKI JAKARTA & 323 \\
\hline 2 JAWA BARAT & 381 \\
\hline 3 JAWA TENGAH & 242 \\
\hline 4 DI YOGYAKARTA & 124 \\
\hline 5 JAWA TIMUR & 327 \\
\hline 6 NANGROE ACEH DARUSSALAM & 95 \\
\hline 7 SUMATERA UTARA & 239 \\
\hline 8 SUMATERA BARAT & 107 \\
\hline 9 RIAU & 69 \\
\hline $10 \mathrm{JAMBI}$ & 37 \\
\hline 11 SUMATERA SELATAN & 106 \\
\hline 12 LAMPUNG & 72 \\
\hline 13 KALIMANTAN BARAT & 40 \\
\hline 14 KALIMANTAN TENGAH & 22 \\
\hline 15 KALIMANTAN SELATAN & 40 \\
\hline 16 KALIMANTAN TIMUR & 62 \\
\hline 17 SULAWESI UTARA & 49 \\
\hline 18 SULAWESI TENGAH & 29 \\
\hline 19 SULAWESI SELATAN & 203 \\
\hline 20 SULAWESI TENGGARA & 35 \\
\hline 21 MALUKU & 22 \\
\hline 22 BALI & 52 \\
\hline 23 NUSA TENGGARA BARAT & 45 \\
\hline 24 NUSA TENGGARA TIMUR & 36 \\
\hline 25 PAPUA & 39 \\
\hline 26 BENGKULU & 17 \\
\hline 27 BANTEN & 102 \\
\hline 28 MALUKU UTARA & 15 \\
\hline 29 KEPULAUAN BANGKA BELITUNG & 14 \\
\hline 30 GORONTALO & 11 \\
\hline 31 IRIAN JAYA BARAT & 17 \\
\hline 32 KEPULAUAN RIAU & 27 \\
\hline 33 SULAWESI BARAT & 17 \\
\hline Grand Total & 3016 \\
\hline
\end{tabular}

Furthermore, the existence of the college has spread in 300 cities / districts across Indonesia. These data show that when the number of cities / districts across Indonesia as much as 471 cities (Ministry of Home Affairs in the National Conference III APEKSI in Solo, 2008), then 64\% have had college. However, college is not spread evenly and not even proportional to the number of existing students. Advancement of information and communication technology currently carries a variety of changes in human life. Role of Information and Communication Technology (ICT) is increasingly felt in various sectors, particularly in education. The role of ICT in education is expected to improve the quality of education as one of the pillars of nation building. Improving the quality of education to be a priority with the realization that success in the future of a nation depends on the quality of education. Therefore, the Ministry of Education and Culture was seriously put the pillars of education through the mission, known as 6K, for instance: Availability, Affordability, Quality, Relevance and Culture, Equity and Certainty [3].
Table 2. The number of applicants/registrants new students at all universities in Indonesia in the group of science in college 2011/2012

\begin{tabular}{|c|c|c|c|c|c|c|}
\hline \multirow[b]{2}{*}{ Num. } & \multirow[b]{2}{*}{ FIELD OF STUDY } & \multirow[b]{2}{*}{ MALE } & \multirow[b]{2}{*}{ FEMALE } & \multirow[b]{2}{*}{ STUDENTS } & \multicolumn{2}{|c|}{ AVERAGE OF NUMBER OF } \\
\hline & & & & & STUDY PROGRAM & $\begin{array}{c}\text { APLICANTS/STUDY } \\
\text { PROGRAM }\end{array}$ \\
\hline \multicolumn{2}{|r|}{ MATHEMATICS AND } & & & & & \\
\hline \multicolumn{2}{|c|}{1 NATURAL SCIENCE } & 21,062 & 35,556 & 56,618 & 576 & 150.38 \\
\hline \multicolumn{2}{|c|}{2 EDUCATION } & 97,854 & 148,402 & 246,256 & 1,968 & 125.13 \\
\hline \multicolumn{2}{|c|}{3 SOCIAL } & 71,877 & 62,186 & 134,063 & 2,047 & 65.49 \\
\hline \multicolumn{2}{|c|}{4 ARGRICULTURE } & 40,791 & 34,489 & 75,280 & 1,153 & 65.29 \\
\hline \multicolumn{2}{|c|}{5 HUMANITIES } & 12,932 & 21,041 & 33,973 & 541 & 62.8 \\
\hline \multicolumn{2}{|c|}{6 ECONOMICS } & 60,051 & 65,345 & 125,396 & 2,592 & 48.38 \\
\hline \multicolumn{2}{|c|}{7 ARTS } & 6,464 & 3,000 & 9,464 & 241 & 39.27 \\
\hline \multicolumn{2}{|c|}{8 ENGINEERING } & 115,580 & 43,621 & 159,201 & 4,163 & 38.24 \\
\hline \multicolumn{2}{|c|}{9 HEALTH AND MEDICINE } & 21,226 & 48,342 & 69,568 & 2,033 & 34.22 \\
\hline \multirow{2}{*}{\multicolumn{2}{|c|}{10 RELIGION }} & 620 & 440 & 1,060 & 50 & 21.2 \\
\hline & & 448,457 & 462,422 & 910,879 & 15,364 & 65.04 \\
\hline
\end{tabular}

The data in Table 2 shows that the field of Engineering is the most numerous organized by the college in demand by the public in the second after Science Education; the respective number of devotees as much as 159.201 people and 246.256 people prospective students. Even in the second, given the number of courses very much, the average reception capacity study program in the field of Science and Engineering for new students in 2011 was very small; ie, only amounted to 38.24 students. Science Education for the group average is the highest, amounting to 125.13 the prospective students.

Data average number of students related to the field of science above implies that if the number of student applicants are constant and the number of courses continues to increase, the study program in the field of engineering science semain unhealthy. It is because the number of study programs too much while freshmen applicants are relatively very limited. Similarly, the conditions for a group of other fields of science, for instance, in the fields of Arts, Religion, and Health Sciences. Field of Economics also relatively saturated average meningat applicants for each program of study only at 48.38 the prospective student and the figure is still below the overall average of 59.29 that the prospective students.

On the other hand, learning resources is one of the aspects of education that must be available, affordable, high quality, relevant to the needs of society, and are accessible to all, with no discrimination based on sex, age, religion, race, and is guaranteed certainty in accessibilities. Currently the achievement of these goals can be accomplished with a single word that is "technology". The development of information and communication technology has been so rapid, those has an impact on the ease of social networking, and have access to information, as well as interacting directly with no limits of space and time.

In order to carry out its mission to achieve the vision of the Ministry of Education and Culture has attempted to open up access using network technology and communication technology. The presence of Electronic School Books, and Home Learning is a powerful tool for students to learn without knowing their existence and time. Learning is very efficient, because the same learning resources that can be used by thousands of people at the same time. Learning will appeal particularly to students, if the information is presented in easy to understand these facilities, please, make the participants learn more and more curious to know, and cheap. Content that is complete, clear, growing interest in learning, will be 
favored to the growing community of intelligent, knowledgerich, even capable of developing science through experiments, research, studies that will ultimately empowered with the development of competence.

Achievement of the above mission, especially at the college level has not been encouraging with the facts that: the limited capacity of the college; universities is low affordability due to the uneven distribution thereby increasing the cost of tuition and accommodation; most universities yet have adequate resources and quality education, quality universities more concentrated on the island of Java; Have not been able to achieve higher education and equal quality; Have not been able to guarantee the fulfillment of the needs and demands of higher education quality. Therefore, special strategies are needed to be able to provide high-quality education that is affordable for the whole Indonesian nation in a short time and low cost.

Through Online Learning program Indonesia Open and Integrated (PDITT), Directorate General of Higher Education (Higher Education) with several participating universities to organize lectures online as real action to resolve these issues over the long term. In the short term we strive to improve the quality of lectures at universities is carried out through a network to be realized as an online college. Improving the quality of lectures in the network is achieved through the application of process standards and content standards in the development of courses held in PDITT platform. Content standards and process standards is based on national standards of education and ISO 19796 and ISO 29163 [3].

\section{LITERATURE REVIEW}

\subsection{Collaborative Learning}

Collaborative Learning method refers to a method of learning that focuses on the success of the process. Unlike the cooperative learning methods, which focus on results. In language both mean the same work. Collaboration comes from the Latin, while the cooperative from English (United States). Collaboration refers to the philosophy of interaction and personal lifestyle, whereas a more cooperative interaction illustrates a structure designed to facilitate the achievement of a particular outcome or goal. The importance of collaborative learning methods assumes cooperative collaboration, working together in the community. In one community or group competition does not occur, but rather to work together to achieve a common goal. In the classroom, when a teacher does this, it is called collaborative learning [4].

Collaborative learning model has been shown to open up great opportunities to learners to participate actively in a chain of teaching and learning activities. As an approach to learning methods, models of collaborative learning involves the active participation of students and suppress or minimize the differences-differences between individuals. This model study has added great momentum to bring formal education and non-formal education.

Philosophically, model of collaborative learning has meaning as: (1) Self-reflection is practical for students live a life outside the classroom activities still require the collaboration system is good in the real world, (2) Defining the better, meaning the students in reality not escape from the social interaction activities in order to attempt learning systems have meaning and significance, and (3) Learning requires couples to be able to share knowledge and add manjemen knowledge (knowledge management), students need a partner or spouse as a way to interact.
Some characteristics of the model of collaborative learning, namely: (1) Learning by doing, students are required to be able to have the initiative and active participation in the learning process, (2) Motivation Instristik, the motive becomes active or function they do not need to be stimulated from the outside, because inside every individual has no urge to do something, (3) Knowledge of dynamic, knowledge development has the potential for resource management, learning becomes one of the key priorities, (4) Students Based Requirements, the intention is in learning activities interests and abilities of students will determine the need -kebutuhan to be met by the manager, and (5) democratic learning, in addition to mastery of the technical aspects of the students are also required to uphold the values of mutual respect and value the opinions when interaction takes place on the concept of this collaborative learning [5].

\subsection{Learning Architecture}

Another approach to instructional models adjusted based learning architecture. Learning can be modeled into four different learning architectures, which is presented in Table 3 .

\section{Table 3. Instructional Architecture Model}

\begin{tabular}{ll}
\hline Learning Model & \multicolumn{1}{c}{ Description } \\
Receptive & This model puts students in a \\
passive role as listener or \\
observer. The presentation in the \\
form of a long exposure without \\
questioning or row of the display \\
on the screen without \\
interactivity. In this model the \\
student is completely passive and \\
not able to determine the \\
sequence and duration of events. \\
This model puts students on a \\
more active role. Learning \\
directive presents the material in \\
the form of small sections were \\
immediately followed by an \\
opportunity to interact and \\
exercises to apply the knowledge \\
that is being studied. Although \\
the students more active role, but \\
they are not in control of the \\
sequence and duration of \\
learning. \\
Guided discovery learning \\
models, its main base is problem \\
solving. Ideally, the problem \\
given to students is a replica of \\
the type of problems to be faced \\
in the world of work. Learners \\
also receive support materials in \\
the form of techniques, methods \\
or ways can be used to solve \\
these problems. \\
Exploration model study \\
provides a collection of materials \\
in bulk and complex for students \\
to learn something new. In this \\
model, learning is not guided or \\
directed in a way. Learners are \\
free to choose from the many \\
learning experiences provided for \\
the control of a new knowledge.
\end{tabular}

\section{PROPOSED LEARNING DESIGN 3.1 Collaborative Learning Maps}

The embodiment of the design principles mentioned above as well as how to answer these questions pursued through the development process KDITT based on ISO 19 796: Part 1, 
which includes the process of developing learning systems, education \& training. Stages or steps recommended development are illustrated in Figure 1 [4].

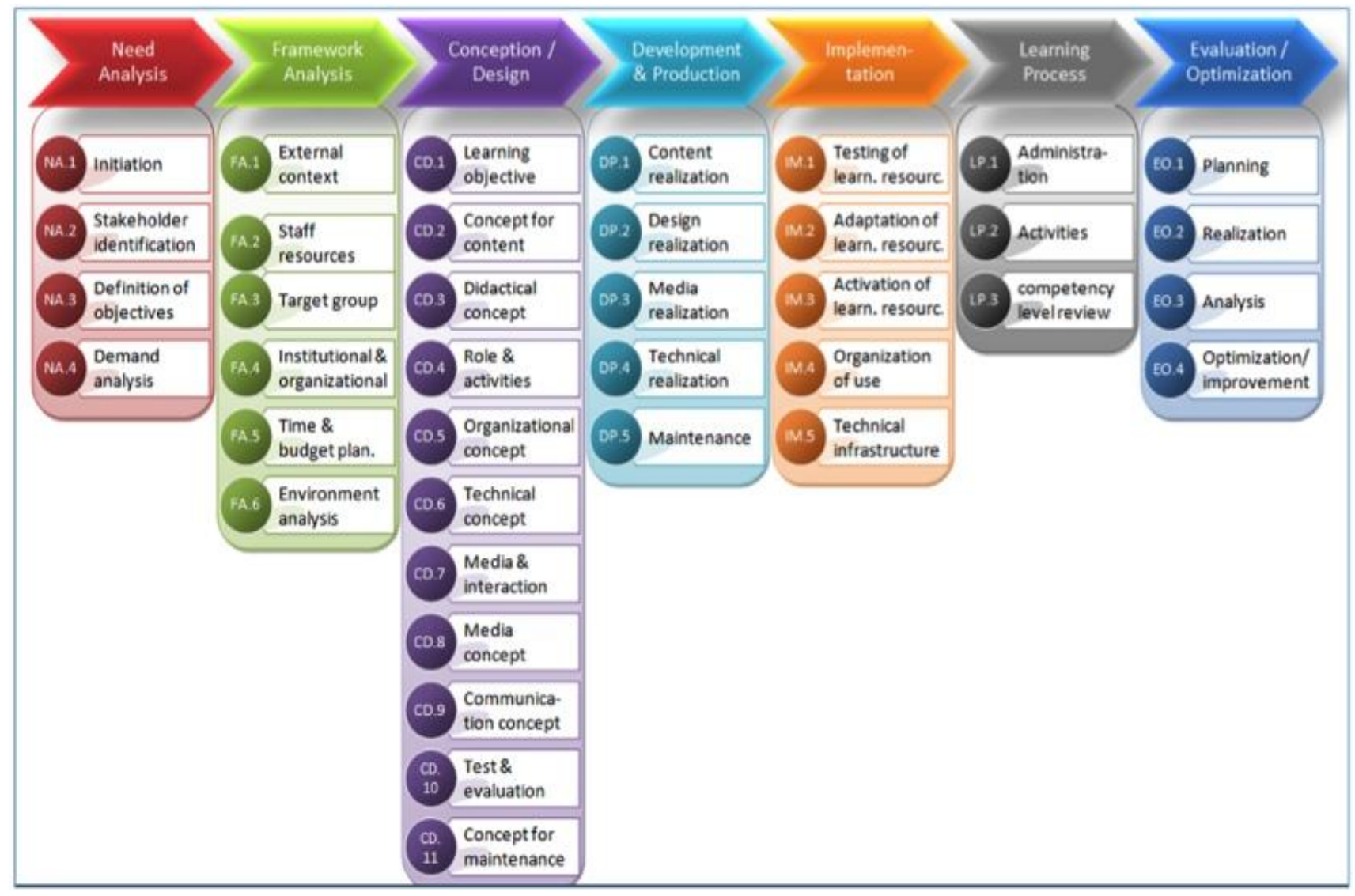

Figure 1. Reference Framework for Description of Quality

\subsection{Maps Dynamic Collaborative Learning}

Maps are a visual collaboration will produce content rich and interesting, because it is designed specifically for the advanced aspects of the dialogue in small teams through coaching activity based on a sequence of self-facilitated occurrences. In this methodology, the communication between entities or actors learning will be accommodated based on the deconstruction of a business solution in an interactive and effective. Interactivity takes place during the process, participants will perform the development and understanding of the material based on real time, and use the learning scenarios are realistic $[4,6,7]$.



Figure 2. Maps Dynamic Collaborative Learning
In the picture above can be seen that each indicator has a level of interactivity in a comprehensive entity [8]. Business solutions offered by this model promises a high level of participation among the participants. For further descriptions for each variable, can be seen in Table 3 below:

Table 3. Maps Dynamic Collaboration Learning Description

\begin{tabular}{ll}
\hline \multicolumn{1}{c}{ Maps Variable } & \multicolumn{1}{c}{ Description } \\
Effective & $\begin{array}{l}\text { Dynamic Collaborative } \\
\text { Learning based on adult } \\
\text { learning methodologies, and } \\
\text { proven to help participants } \\
\text { more easily to translate } \\
\text { concepts and new information } \\
\text { more quickly. The model will } \\
\text { also open in the open } \\
\text { perspective due to the better } \\
\text { aspects of knowledge } \\
\text { absorption. } \\
\text { Due to the method of } \\
\text { Dynamic Collaborative } \\
\text { Learning is independent and is } \\
\text { designed to allow participants } \\
\text { to facilitate themselves, they } \\
\text { can use the service group with } \\
\text { a limited number of } \\
\text { participants at different times }\end{array}$ \\
\hline
\end{tabular}


and locations. This is certainly going to make a different atmosphere when using other similar methods of learning.

Engaging and Fun $\quad \begin{aligned} & \text { One of the unique characters } \\ & \text { of this method is the learning } \\ & \text { process that uses a model of } \\ & \text { discussions in small groups to } \\ & \text { do a disagreement that will } \\ & \text { create a solid group. } \\ & \text { Another advantage of the } \\ & \text { method is Collaborative } \\ & \text { Learning Maps have proved } \\ & \text { successful in the } \\ & \text { implementation of some of the } \\ & \text { topics, and the topic can be } \\ & \text { designed to achieve the } \\ & \text { learning objectives. } \\ & \text { Collaborative Learning Maps } \\ & \text { method allows participants to } \\ & \text { dissolve in the learning } \\ & \text { process so as to create } \\ & \text { harmonious conditions among } \\ & \text { participants and educators. }\end{aligned}$
Experiential

\subsection{Benefits of Learning Design}

In addition to producing a draft proposal of a collaborative learning system mapping, this study may also explain some of the advantages of its implementation, among others:

1) Better Retention. The combination of learning and working with collaborative learning process mapping system can help participants remember well. The experience of understanding of the content and results of communication between entities or actors proven to replace the system of learning with traditional paradigms.

2) True Internalization. With a characteristic that combines technical knowledge and social aspects of the mapping of the collaborative learning process can help participants can truly internalize the core message delivered.

3) Predictable Results. Collaborative learning system based mapping also through the stages of testing to ensure predictable results. Thus, either the manager or the actor teachers can define decision support systems to monitor performance and evaluate each student.

4) Alignment and Momentum. By developing a common understanding on an organization or institution together, then this mapping system can achieve the goals or the maximum momentum of predetermined.

5) Shared Vision of Success. This model not only to carry out a shared vision for success in the learning process but also develop an understanding of how they will contribute to a comprehensive.
6) Holistic Understanding. One of the important missions of this learning system is to provide provisioning capabilities as a context for understanding the individual, the more likely that they understand the higher the chance to have the ability to be a complex initiative.

7) Team Building. Creating custom communication between entities in terms of discussion and deliberation, learning, collaboration can help participants to get to know each other and cooperate with effective ways accompanied with prior experience.

8) Cost Effective. The mapping process is collaborative learning provide better engagement and retention at a cost that is comparable or better than learning methods with other models.

Thus, the formulation proposed in this study is expected to provide alternative solutions in the application of PDITT amid problems in terms of the gap between the qualities of learning in the area of Indonesia are very heterogeneous and dynamic.

\section{CONCLUSION}

Initiating the capacity and capability of the education system in Indonesia cannot be simply a way to develop the infrastructure and information systems of learning in it alone. There needs to be a great plan contained in the grand design of the learning system so that all the people of Indonesia without exception can enjoy a better learning system. This research has produced a formulation in which the Dynamic Collaborative Learning into the core framework is shown to accommodate the needs of local and indigenous of Indonesia society. For future work, this formulation need to implemented on institution higher education in Indonesia.

\section{REFERENCES}

[1] Dirjen DIKTI (2009). "Perspektif Perguruan Tinggi Indonesia 2009"

[2] Ditjen Dikmen (2013). "Renstra Ditjen Dikmen 2013"

[3] (http://pditt.belajar.kemdikbud.go.id/.), 2014.

[4] Dirjen Dikti (2014), "Pengembangan dan Penyelenggaraan Kuliah Daring Indonesia Terbuka \& Terpadu (KDITT)"

[5] Emigawaty. 2015. Pemanfaatan Konsep Ontology Dalam Interaksi Sistem e-Learning. Jurnal Dasi Vol. 16 No. 3 September 2015. ISSN: 1411-3201.

[6] Terenzini, Patrick (2001). "Collaborative Learning vs. Lecture/Discussion: Students' Reported Learning Gains”

[7] Sanna Järvelä, (2012). "Structuring and Regulating Collaborative Learning in Higher Education with Wireless Networks and Mobile Tools"

[8] K-E.Chang, (2003). "Web-based collaborative inquiry learning" 